\title{
Self Monitor Scale
}

National Cancer Institute

\section{Source}

National Cancer Institute. Self Monitor Scale. NCI Thesaurus. Code C121466.

A rating scale included in the Behavior Rating Inventory of Executive Function (BRIEF) that assesses aspects of social or interpersonal awareness. It captures the degree to which a person is aware of the effect that their behavior has on others and how it compares with standards or expectations for behavior. 